\title{
Poor Involvement of General Practitioners in Decisions of Withholding or Withdrawing Life-Sustaining Treatment in Emergency Departments
}

\author{
Marion Douplat, MD PhD ${ }^{1,2}$, Khadidja Daoud, $M D^{3}$, Julien Berthiller, $M S^{4}$, \\ Anne-Marie Schott, MD, $P h D^{4}$, Véronique Potinet, $M D^{7}$, Pierre Le Coz, MD PhD', \\ Karim Tazarourte, $M D P h D^{5}$, and Laurent Jacquin, $M D^{5}$
}

\begin{abstract}
'Hospices Civils de Lyon, Hôpital Lyon Sud, Service d'Accueil des urgences, Pierre Bénite, France; ${ }^{2}$ Aix-Marseille Université/EFS/CNRS, UMR 7268 ADéS, Faculté de Médecine, Marseille, France; ${ }^{3}$ Hôpital de Vienne, Service d'Accueil des urgences, Vienne, France; ${ }^{4}$ Pôle Information Médicale Evaluation Recherche, Hospices Civils de Lyon/University Claude Bernard Lyon 1 /HESPER EA 7425, Lyon, France; ${ }^{5}$ Hospices Civils de Lyon, Hôpital Edouard Herriot, Service d'Accueil des urgences, Lyon, France.
\end{abstract}

BACKGROUND: Decisions of withholding or withdrawing life-sustaining treatment are frequent in emergency departments (ED) and patients are often unable to communicate their wishes concerning end of life desires.

OBJECTIVE: To evaluate the participation of general practitioners (GPs) during the decision-making process of withholding or withdrawing life-sustaining treatments in ED.

DESIGN: Prospective observational multicenter study. PATIENTS: We included patients for whom a decision of withdrawing or withholding life-sustaining treatments was made in ED. For each patient, we enrolled one general practitioner.

MAIN MEASURES: GPs were interviewed about their perception of end of life patient's management and the communication with ED and families.

KEY RESULTS: There were 109 potential patient participants. We obtained answers from 54 (49.5\%) of the patient's associated GPs. Only 4 (7.4\%) GPs were involved during the decision-making process of withholding or withdrawing life-sustaining treatments. Among GPs, 29 (53.7\%) were contacted by family after the decision, most often to talk about their difficult experience with the decision. A majority (94\%) believed their involvements in these decisions were important and 68\% wished to "always" participate in end of life decisions despite the fact that they usually don't participate in these decisions. Finally, $66 \%$ of GPs believed that management of end of life in the emergency department was a failure and should be anticipated.

CONCLUSIONS: GPs would like to be more involved and barriers to GP involvement need to be overcome. We do not have any outcome data to suggest that routine involvement of GPs in all end of life patients improves their outcomes. Moreover, it requires major system and process-based changes to involve all primary care physicians in ED decision-making.

Electronic supplementary material The online version of this article (https://doi.org/10.1007/s11606-019-05464-y) contains supplementary material, which is available to authorized users.

Received November 13, 2018

Accepted September 30, 2019

Published online November 8, 2019

\section{NIH TRIAL REGISTRY NUMBER: NCT02844972}

KEY WORDS: general practitioners; emergency services; decision-making; terminal care; primary care.

J Gen Intern Med 35(1):177-81

DOI: $10.1007 / \mathrm{s} 11606-019-05464-y$

(C) Society of General Internal Medicine 2019

\section{INTRODUCTION}

Most deaths in emergency departments (ED) are preceded by a decision of withholding or withdrawing life-sustaining treatments and most of these patients are unable to communicate their wishes or participate in the decision. ${ }^{1-3}$ The context of emergency medicine, the lack of time, and the lack of a relationship with the patients add difficulties for physicians to initiate an informed decision of withdrawing or withholding life-sustaining treatments. Decisions of end of life have been shown to be difficult and complex for emergency physicians, ${ }^{4}$ particularly in the absence of advance directives. ${ }^{5}$ Indeed, a majority of patients have not written their advance directives beforehand. General practitioners (GPs) could be a source of information about wishes concerning patients' end of life. In a previous study, GPs were shown to be a good choice for third-party intervention in making end of life decisions for hospitalized patients. ${ }^{6}$ Unfortunately, medical advice is currently sought from GPs in less than $5 \%$ of cases. ${ }^{2}$

The prevalence of end of life discussions varies across countries. $^{7}$ A recent study demonstrated poor communication in decision-making between practitioners and families at concerning non-communicating patients suffering from dementia but underlined that the decision-making process could be improved with better anticipation. ${ }^{8}$ Our study's purpose is to describe the involvement of GPs during the decisionmaking-process of withholding or withdrawing lifesustaining treatments in the ED. 


\section{METHODS}

\section{Study Design and Setting}

We conducted a prospective observational multicenter study in 3 EDs of University hospitals in France between September 2015 and December 2016. The study was approved by the institutional ethics committee and follows the STROBE recommendations.

\section{Selection of Participants}

We enrolled adult patients unable to communicate and for whom a decision of withdrawing or withholding lifesustaining treatments was undertaken. For each patient, we included their general practitioner, defined as the physician who knew and followed the patient prior to the ED visit.

The decision-making process of these decisions was held as per usual by the emergency physician and GPs were contacted to inquire about their thoughts and their involvement after the fact. GPs were interviewed about their general perception of end of life patients' management and the communication with ED and families about a patient. The GPs survey is presented in the ESM. If the same GP had multiple patients the survey response only counted once.

Informed consent was obtained from relatives after the decision to withdraw or withhold life-sustaining treatments was made. Relatives were defined as all the individuals aged 18 and above who were present with the patient in the ED in the following order: spouse $>$ adult child $>$ other family or friend relationship. We excluded patients without relatives and GP.

\section{Data Collection}

Data about general practitioners included: age, sex, years of experience, environment of practice (classified with urban or rural), number of end of life patients followed per year, and end of life management training, which we defined as at least $10 \mathrm{~h}$ of classes over the two previous years.

Data concerning physicians' perception during the decision-making process were obtained with Likert scaled (" never », " sometimes », " often », or « always») and closed questions.

\section{Definition}

Patients unable to communicate in ED were described as acute loss of consciousness without a Glasgow score threshold, chronic vegetative state, or advanced dementia. Advanced dementia was defined by a mini-mental state (MMS) under 10. This evaluation was realized by the emergency physician who enrolled the patient.

End of life patient population in GP practice was defined as having a survival prognosis of less than 6 months.

Withdrawal was defined as a discontinuation of treatments that had previously been implemented, and withholding was defined as a predetermined decision not to implement therapies that would otherwise be deemed necessary because they were considered unlikely to modify the outcome in these particular instances. Therapies included mechanical ventilation, vasopressor, and inotropes, noninvasive ventilation, renal replacement therapy, intravenous fluid expansion, and oxygen at high rate. We did not include antibiotic which was not considered as an aggressive care.

\section{Endpoints}

General practitioners were interviewed by phone within two weeks of the sentinel ED visit. The interview was conducted by an emergency physician who did not participate in the care of included patients and 5 attempts were made to contact the general practitioners.

\section{Statistical Analysis}

Only general practitioners with a complete follow-up were considered for statistical analysis. Statistical analysis was performed using SPSS 22.0 (Chicago, IL). Quantitative variables are expressed as mean and standard deviation. Qualitative data are expressed as $n$ and percentages.

\section{RESULTS}

\section{Characteristics of General Practitioners}

There were 109 potential patient participants. We obtained answers from $54(49.5 \%)$ of the patient's associated general practitioners; 4 GPs had 2 patients enrolled. Our study's flow chart is provided in Figure 1. General Practitioners averaged 54 years of age and the majority worked in an urban environment. Table 1 shows the characteristics of participating general practitioners. Death in ED occurred for 47 patients (43.1\%), and after 21 days, $84(77.1 \%)$ patients had died in hospital. Eight patients $(7.3 \%)$ were not hospitalized and returned to their living place.

\section{General Perception of End of Life Patients' Management}

We asked GPs about their general perception of their implication in the decision of withholding or withdrawing lifesustaining treatment (Table 1). Less than half $(46.0 \%)$ reported having "always" discussed end of life with patients who had a chronic disease. More often, the subject was broached by the family. More than two-thirds of GPs (66.0\%) thought that end of life in ED was a failure and nearly half (46.0\%) felt that end of life patients should not be admitted to the hospital. The majority (94.0\%) thought that their involvement in these decisions was important and $68.0 \%$ wished to "always" participate in end of life decisions for their ED patients in the future; $68.0 \%$ of GPs felt that they would have sufficient time in their practice to participate in these decisions. 


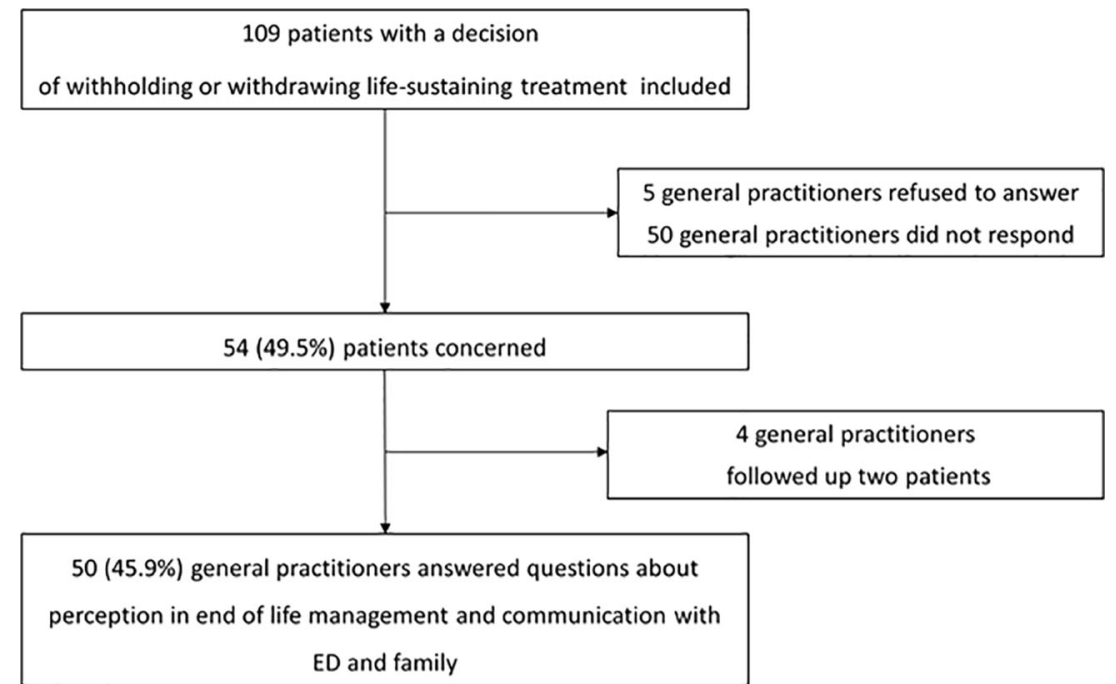

Figure 1 Trial profile of general practitioners during study period.

Table 1 General Practitioner Characteristics and Perception of End of Life Patient's Management

\begin{tabular}{|c|c|}
\hline Characteristic & $n=\mathbf{5 0}$ \\
\hline Age $($ mean $\pm \mathrm{SD})$ & $53.6 \pm 14.6$ \\
\hline Women & $13(26.0 \%)$ \\
\hline Years of experience & $24.1 \pm 11.6$ \\
\hline \multicolumn{2}{|l|}{ Environment of practice } \\
\hline Urban & $37(74.0 \%)$ \\
\hline Rural & $13(26.0 \%)$ \\
\hline \multicolumn{2}{|l|}{ Number of end of life patients followed per year } \\
\hline Less than 5 & $23(46.0 \%)$ \\
\hline 5 to 10 & $8(16.0 \%)$ \\
\hline More than 10 & $19(38.0 \%)$ \\
\hline End of life management training (yes) & $16(32.0 \%)$ \\
\hline \multicolumn{2}{|l|}{ General perception in end of life management } \\
\hline \multicolumn{2}{|c|}{ End of life wishes was discussed with concerned patients } \\
\hline Always & $23(46.0 \%)$ \\
\hline Often & 0 \\
\hline Sometimes & $24(48.0 \%)$ \\
\hline Never & $3(6.0 \%)$ \\
\hline \multicolumn{2}{|l|}{ The way the subject was broached } \\
\hline Family initiative & $29(58.0 \%)$ \\
\hline Physician initiative & $26(52.0 \%)$ \\
\hline Patient initiative & $20(40.0 \%)$ \\
\hline \multicolumn{2}{|l|}{ Decision not to admit an end of life patient in hospital } \\
\hline Always & 0 \\
\hline Often & $23(46.0 \%)$ \\
\hline Sometimes & $25(50.0 \%)$ \\
\hline Never & $2(4.0 \%)$ \\
\hline Management of end of life in ED was a failure & $33(66.0 \%)$ \\
\hline Involvement in these decisions was important & $47(94.0 \%)$ \\
\hline Physicians participating in decision must be present & $11(22.0 \%)$ \\
\hline \multicolumn{2}{|l|}{ Usual participation required in these decision } \\
\hline Always & 0 \\
\hline Often & $2(4.0 \%)$ \\
\hline Sometimes & $20(40.0 \%)$ \\
\hline Never & $28(56.0 \%)$ \\
\hline \multicolumn{2}{|l|}{ Wished participation in these decisions } \\
\hline Always & $34(68.0 \%)$ \\
\hline Often & 0 \\
\hline Sometimes & $14(28 \%)$ \\
\hline Never & $2(4.0 \%)$ \\
\hline $\begin{array}{l}\text { Practice leave enough time to participate in these } \\
\text { decisions }\end{array}$ & $34(68.0 \%)$ \\
\hline This participation must be valued & $22(44.0 \%)$ \\
\hline
\end{tabular}

Data are expressed as $N(\%)$, unless otherwise indicated

\section{General Practitioner Communication with ED and Families of End of Life Patients}

Few of the interviewed $(9.3 \%)$ had sent these patients to the ED and less than half $(44.0 \%)$ were aware of the patient's admission (Table 2). Most commonly, they were advised after patient discharge. About a fifth $(20.4 \%)$ reported receiving a call from emergency physicians to get additional patient information; this was largely about the patient's medical history.

Table 2 General Practitioner Communication with Emergency Departments and Families of End of Life Patients

\begin{tabular}{ll}
\hline \hline Communication with ED & $\boldsymbol{n}=\mathbf{5 4}$ \\
\hline Decision to admit patient in ED & $5(9.3 \%)$ \\
Aware of patient admission & 24 \\
& $(44.0 \%)$ \\
The way GP was advised & 13 \\
By family & $(24.1 \%)$ \\
& $7(13.0 \%)$ \\
By hospital discharge letter & $5(9.3 \%)$ \\
By hospital call & $3(5.6 \%)$ \\
By GP initiative to call & 11 \\
Call received from emergency physician to get & $(20.4 \%)$ \\
information about the patient & $8(14.8 \%)$ \\
Type of information asked by the emergency physician & $5(9.3 \%)$ \\
Medical past history & $2(3.7 \%)$ \\
Autonomy/life quality of the patient & $2(3.7 \%)$ \\
Existence of advance directives & $4(7.4 \%)$ \\
Existence of a trustworthy person & 48 \\
Involved in the decision of WH/WD & $(88.9 \%)$ \\
Agreement with the decision of WH/WD & $n=54$ \\
& 29 \\
Communication with family & $(53.7 \%)$ \\
Contact with the family following the decision & 11 \\
Reason the family talked about the decision & $(20.4 \%)$ \\
Difficult experience with the decision & $7(13.0 \%)$ \\
& $3(5.6 \%)$ \\
Medical information about the patient & \\
Misunderstanding of the decision &
\end{tabular}

Data are expressed as $N(\%)$, unless otherwise indicated WH withholding, WD withdrawing 
There were few calls about the existence of advance directives or a trustworthy person. Finally, only 4 (7.4\%) GPs were involved during the decision-making process of withholding or withdrawing life-sustaining treatments, though most (88.9\%) GPs agreed with the decision. Among the GPs, the majority (53.7\%) were contacted by family members after the decision, most often to talk about their difficult experience with the decision.

\section{DISCUSSION}

We found that very few GPs were involved in the decision-making process of withholding or withdrawing life-sustaining treatments during the ED visit, although most of them would like to participate. Importantly, our GPs felt that time was not an obstacle. GPs can be a valuable source of information regarding the premorbid condition of the patients and their wills and wishes and can help ED providers to set appropriate treatment goals, especially in the context of end of life decisions. Our results are similar to previous studies. GPs were rarely involved in ED end of life decisions and GPs felt that their participation was important and that time would not be an obstacle for involvement. ${ }^{2,6}$

The involvement of GPs is crucial in ED decision-making and numbers of guidelines recommend direct involvement of GPs. ${ }^{9-11}$ But both specialties face challenges in end of life care. On the one hand, ED are not the most appropriate place to give end of life care ${ }^{12}$ even though many patients came to die in the ED. ${ }^{1,2,13}$ Ethical aspects must be respected in end of life decisions such as the respect of the patient's autonomy and the non-malfeasance principle. ${ }^{14}$ Emergency physicians must take the best treatment option which gives most overall benefit and is least restrictive of the patient's future choices. GPs seem not to be identified by the ED as a source of information concerning patients' end of life wishes even if it was discussed previously. On the other hand, GPs should help emergency physicians to discuss the level of care for their patients. Even if it would not be reasonable for the GPs to be reachable in the middle of the night, they could be included in the decisionmaking in the following days especially for noncommunicating patients.

Another challenge between the two specialties is the end of life communication. GPs should discuss end of life wishes with concerned patients. Indeed, most patients didn't have advance directives before admission in the ED. ${ }^{15}$ It could help to avoid sending them to the ED. It has been found that the main perceived barriers of GP-patient communication in palliative care are the lack of availability of GPs and also GPs' ambivalence to discuss 'bad prognosis. ${ }^{16,17}$ Similarly, emergency physicians should ask patients or families whether they have made advance directives or any advance care plans with their GP.
GPs have also expressed dissatisfaction with ED communication including discharge letters not reaching GPs and deficiencies in the discharge information from the ED. ${ }^{18}$ Discharging dying patients from the ED may be appropriate and a care plan must be initiated and continued at home as it is recommended. ${ }^{10,11}$ Moreover, copies of a discharge letter should be given to the family, care homes, and the GP. Previous studies have shown benefit to communicating with GPs. A call to the GP was found to significantly decrease the patients' ED waiting time and the studies avoided by this contact were found to result in significant cost savings. ${ }^{19}$

The last challenge in the context of end of life decision is the communication between families and GPs. After a death, the care given to the patient's family has a major influence on how they grieve. ${ }^{20,21}$ The ED can be a difficult place to care for the bereaved family. Rapid time management constraints and the chaotic work environment in ED could impact communication with the family. Because of the lack of information concerning the decision-making process, it could be difficult for GPs to help the bereaved patients.

Based on our results, several recommendations can be proposed. Firstly, including GPs in the decision-making process could help emergency physicians to choose the best treatment option. Secondly, GPs and ED should initiate end of life care planning which should be clearly documented and communicated between the two specialties. Eventually, communication based on a multidisciplinary approach including physicians, nurses, psychologists in the ED, and GPs could help families to better endure their ED experience.

Our study has a number of strengths and weaknesses. Our study was a prospective multicenter trial. Limitations include the low participation rate of GPs, the relatively small sample size, and the lack of data on patient family satisfaction with the care received.

\section{CONCLUSIONS}

In conclusion, our study underlines the importance of improving involvement of GPs in the decision-making process of withholding or withdrawing life-sustaining treatments in emergency departments. GPs wish to participate in these decisions and could serve a central role in improving communication between ED providers, the GPs, and the patients' families.

Availability of Data and Material: The datasets used and/or analyzed during the current study are available from the corresponding author on reasonable request.

Corresponding Author: Marion Douplat, MD PhD; Aix-Marseille Université/EFS/CNRSUMR 7268 ADéS, Faculté de Médecine, 27 Boulevard Jean Moulin 13005, Marseille, France (e-mail: marion. douplat@chu-lyon.fr). 
Authors' Contributions $M D, L J$ conceived the study, designed the trial, and obtained research funding. $M D, K D, L J$, and KT supervised the conduct of the trial and data collection. MD, $L J$ undertook recruitment of participating centers and patients and managed the data, including quality control. $J B$ and $L J$ provided statistical advice on study design and analyzed the data. MD drafted the manuscript, and all authors contributed substantially to its revision. MD takes responsibility for the paper as a whole. All authors read and approved the final manuscript.

Funding Information The study was financed by the APICIL FOUNDATION. The institution "Hospices Civils de Lyon" received the funds for data management and analysis.

\section{Compliance with Ethical Standards:}

Conflict interest: The authors declare that they do not have a conflict of interest.

Ethics Approval and Consent to Participate: The study was approved by the ethics committee of the University Hospital of Lyon on March 12th, 2015.

Publisher's Note: Springer Nature remains neutral with regard to jurisdictional claims in published maps and institutional affiliations.

\section{REFERENCES}

1. Le Conte $\mathbf{P}$, Baron $\mathbf{D}$, Trewick $\mathbf{D}$, et al. Withholding and withdrawing life-support therapy in an Emergency Department: prospective survey. Intensive Care Med. 2004 Dec; 30(12):2216-21.

2. Le Conte $\mathbf{P}$, Riochet $\mathbf{D}$, Batard $\mathbf{E}$, et al. Death in emergency departments: a multicenter cross-sectional survey with analysis of withholding and withdrawing life support. Intensive Care Med. 2010 May; 36(5):765-72.

3. Damghi N, Belayachi J, Aggoug B, Dendane T, et al. Withholding and withdrawing life-sustaining therapy in a Moroccan Emergency Department: an observational study. BMC Emerg Med. 2011 Aug 12;11:12.

4. Douplat M, Jacquin L, Tazarourte K, Michelet $\mathbf{P}$, Le Coz $\mathbf{P}$, Physicians experience in decisions of withholding and withdrawing life-sustaining treatments: a multicentre survey into emergency departments, Anaesthesia Critical Care and Pain Medicine (2018) Dec;37(6):633-634

5. Wall J, Hiestand B, Caterino $\mathbf{J}$ (2015) Epidemiology of Advance Directives in Extended Care Facility Patients Presenting to the Emergency Department. West J Emerg Med 16:966-973.

6. Ferrand E, Jabre P, Fernandez-Curiel s, et al. Participation of French general practitioners in end of life decisions for their hospitalised patients. J Med Ethics. 2006 Dec;32(12):683-7.

7. Evans N, Costantini M, Pasman H.R, End of Life Communication: A Retrospective Survey of Representative General Practitioner Networks in Four Countries. J Pain Symptom Manage. 2014 Mar; 47(3): 604-19.

8. Lamahewa K, Mathew R, Miffe S, Wilcock J, Manthorpe J, Sampson EL, Davies N. A qualitative study exploring the difficulties influencing decision making at the end of life for people with dementia. Health Expect. 2018 Feb;21(1):118-127.

9. A.-L Feral -Pierssens. T Boulain. F Carpentier. P. Le Borgne Withholding and withdrawing life-sustaining therapies from adult patients in emergency care. Ann. Fr. Med. Urgences (2018) 8 :246-251.

10. European Recommendations for End-of-Life Care for Adults in Departments of Emergency Medicine. EUSEM. 2017.

11. Royal College of Emergency Medicine. End of Life Care for Adults in the Emergency Department. London, March 2015.

12. Chan GK. End-of-life models and emergency department care. Acad Emerg Med. 2004; 11(1):79-86.

13. Olsen JC, Bueneffe ML, Falco WD. Death in the emergency department. Ann Emerg Med. 19.

14. Beauchamp TL, Childress J. Principles of Biomedical Ethics (5e édition), New-York/Oxford, Oxford University Press, 2001.98; 31(6):758-765.

15. Douplat M, Berthiller J, Schott AM, Potinet V, Le Coz P, Tazarourte K, Jacquin L. Difficulty of the decision-making process in emergency departments for end of life patients. J Eval Clin Pract. 2019 Jul 9.

16. Slort W, Schweitzer BP, Blankenstein AH, et al. Perceived barriers and facilitators for general practitioner-patient communication in palliative care: a systematic review. Palliat Med. 2011 Sep;25(6):613-29.

17. Slort W, Blankenstein AH, Deliens L, van der Horst HE. Facilitators and barriers for GP-patient communication in palliative care: a qualitative study among GPs, patients, and end-of-life consultants. Br J Gen Pract. 2011 Apr;61(585):167-72.

18. Lane N, Bragg MJ. From emergency department to general practitioner: evaluating emergency department communication and service to general practitioners. Emerg Med Australas. 2007;19:346-352.

19. Montalto M, Harris P, Rosengarten P. Impact of general practitioners' referral letters to an emergency department. Aust Fam Physician. 1994;23:1320-1321.

20. Rubin, W, Sarnoff, J. (1986). Sudden unexpected death: intervention with the survivors. Ann Emerg Med. 15, 99-102.

21. Walters DT, Tupin JP. Family grief in the emergency department. Emerg Med Clin North Am. 1991 Feb;9(1):189-206.

Publisher's Note Springer Nature remains neutral with regard to jurisdictional claims in published maps and institutional affiliations. 